\title{
An Integrated Indexical Assessment of Groundwater Quality of Sukkur City, Pakistan
}

\author{
Muhammad Haseeb Ansari ${ }^{1}$, Ghulam Shabir Solangi ${ }^{1,}$, , Nabi Bux Bhatti ${ }^{2}$, Palwasha Akram ${ }^{3}$, \\ Sallah ud din Panhwar ${ }^{4}$, Faraz Ali Shah ${ }^{1}$, Shahzeb Ansari ${ }^{1}$ \\ ${ }^{1}$ Department of Civil Engineering, Mehran University of Engineering \& Technology, Shaheed Zulfiqar Ali Bhutto Campus, Khairpur Mir's, \\ Pakistan \\ ${ }^{2}$ Sindh Irrigated Agriculture and Productivity Enhancement Project (SIAPEP), Government of Sindh, District Larkana, Pakistan \\ ${ }^{3}$ Department of Analytical Chemistry, Dr. M. A. Kazi, Institute of Chemistry, University of Sindh, Jamshoro, Pakistan \\ ${ }^{4}$ Department of Civil Engineering, Balochistan University of Engineering \& Technology, Khuzdar, Pakistan
}

Email address:

solangi_shabir@yahoo.com (G. S. Solangi)

${ }^{*}$ Corresponding author

\section{To cite this article:}

Muhammad Haseeb Ansari, Ghulam Shabir Solangi, Nabi Bux Bhatti, Palwasha Akram, Sallah ud din Panhwar, Faraz Ali Shah, Shahzeb Ansari. An Integrated Indexical Assessment of Groundwater Quality of Sukkur City, Pakistan. International Journal of Economy, Energy and Environment. Vol. 6, No. 5, 2021, pp. 91-97. doi: 10.11648/j.ijeee.20210605.12

Received: April 29, 2021; Accepted: September 3, 2021; Published: September 14, 2021

\begin{abstract}
Groundwater contamination issues are rising globally, including the Sukkur, Sindh, Pakistan. Due to gravity of the problem and concerns of the people of Sukkur City, the present study was planned to assess the quality of groundwater of Sukkur City based on an integrated indexical approach, i.e., the water quality index (WQI) model. The WQI was calculated using analysis results of various physicochemical parameters of thirty (30) georeferenced groundwater samples randomly collected from the study area. Groundwater samples were analyzed for various physical and chemical parameters such as $\mathrm{pH}$, electrical conductivity (EC), turbidity, total dissolved solids (TDS), calcium (Ca), magnesium (Mg), total hardness (TH), chlorides, nitrates, nitrites, etc. The observed level of $\mathrm{pH}$ in the groundwater samples of the study area ranged in between 7.6 to 8.8. The chloride concentration ranged between 32 to $2280 \mathrm{mg} / \mathrm{l}$. The calcium level ranged between 8 to $440 \mathrm{mg} / \mathrm{l}$. The magnesium concentration observed between 32 to $1710 \mathrm{mg} / 1$ The total hardness level ranged between 40 to $2150 \mathrm{mg} / \mathrm{l}$. The EC and TDS ranged between 0.28 to $8.13 \mathrm{dS} / \mathrm{m}$, and between 180 to $5200 \mathrm{mg} / \mathrm{l}$ respectively. The estimations of the WQI model showed that $2 \%$ of the water samples were excellent, $52 \%$ good, $22 \%$ poor, and $24 \%$ unsuitable for drinking purpose. Overall water quality analysis indicated that some of the areas of the Sukkur city have poor quality groundwater, thus it should be treated before its use for domestic purposes.
\end{abstract}

Keywords: Groundwater, Physicochemical Analysis, WQI, Sukkur, Pakistan

\section{Introduction}

Groundwater is widely used around globe to accomplish drinking, agricultural as well industrial needs. It is reported that about 33\% global population consumes groundwater for drinking, and many other purposes such as for irrigation, agriculture, and industrial purposes since there is an ease in getting less contaminated groundwater as compared to the surface water [1]. Thus, its quality assessment is also very important in order to know its suitability for various uses. Additionally, the groundwater in the old decades was clean and pure but due to increasing development and quick evolution in the industries and factories creating exceptional environmental issues [2]. It is generally an important factor to be considered that once the groundwater is contaminated it is very difficult to maintain its previous purity or quality being served before [3]. It is an incredible need to evaluate the quality of groundwater [4]. Due to increasing number of populations in the world and over-exposure of surface water, the intake of groundwater is increasing day by day because it plays a significant role not only for drinking but also to boost up the economy and stability of a country. 
Water quality assessment is essential to fulfilling the basic requirement of human health in providing the best quality of water [5-11] according to the standards recommended by the World Health Organization (WHO) [12]. It is additionally important that the supply of groundwater resources within the world ought to be taken into full consideration [13]. Other than the shortage of water resources, such as high demand of groundwater assets in the parched and semi-arid areas in which the wastage of water also constantly increasing with the utilization of the water and is responsible for shortage in the groundwater in future, so it is very important to study about the control of groundwater wastage to overcome the shortage.

The key factor is that there is a risk of incredible danger of defilement in the natural resources of groundwater which is the most important challenge of any country since at every different location there is a different type of soil and chemical composition in the water which greatly impact on the quality of groundwater [14]. The anthropogenic components which mostly impact the quality and accessibility of safe drinking water including synthetic organic materials and significant metals like $\mathrm{Zn}, \mathrm{Pb}, \mathrm{Cd}, \mathrm{Cu}, \mathrm{Ni}$, and $\mathrm{Cr}$.

Groundwater quality assessment is an important part of ecological quality and manageability in any society, such type of assessment is significant toward the improvement of human health and the whole biological system of the body. To accomplish this system, water quality assessments are generally done to examine and investigate the degree of different contaminants found in water. At present, the quality of the water is a significant research focused area of numerous scientists around the globe. These quality assessment tests have demonstrated to help sort the water quality of various regions in a straightforward way [15].

Literature reveals that there is a need to consider the quality of groundwater for drinking and irrigation purposes. Thus, the current study has been conducted to determine the overall quality of groundwater collected from Sukkur City for drinking purposes based on an indexical approach namely the Water Quality Index (WQI).

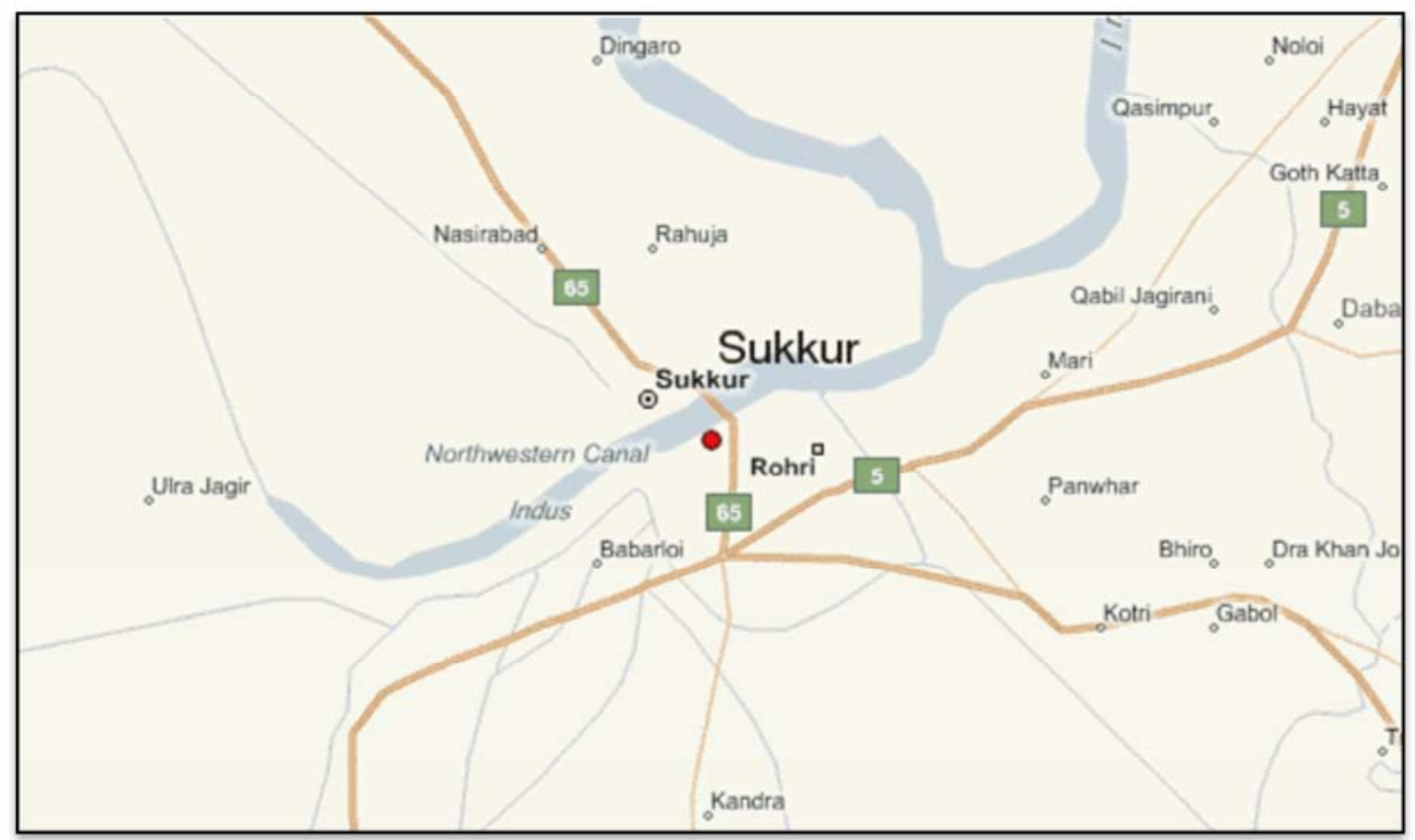

Figure 1. Google Map of the Study Area (Sukkur City).

\section{Materials and Methods}

\subsection{Description of the Study Area (Sukkur City)}

Sukkur is a city in Pakistan's Sindh province, situated on the western bank of the Indus River. It is Sindh's third-largest metropolis, after Karachi and Hyderabad, with a total area of $51,65 \mathrm{~km}^{2}$. During the British era, New Sukkur was founded. It was also known as the "Gate of Sindh" at one time. Location of the study area is shown in Google Map (Figure 1). Lansdowne Bridge connects the study area with Rohri across the Indus River. Its climate is hot, wind speed is low throughout the year, summer is very hot as the temperature reaches up to $50^{\circ} \mathrm{C}$. About 551, 357 people are living in the Sukkur city. Most of the people of the Sukkur city (study area) use groundwater to accomplish their domestic needs.

\subsection{Groundwater Sample Collection and Analysis}

About thirty (30) georeferenced groundwater samples (Figure 2) were randomly collected from different Union Councils (UCs) of the study area. Properly washed half litre capacity bottles were used to collect water samples from hand pumps, electric motors, boreholes installed in the city. The collected water samples were analysed for various 
physical and chemical parameters such as turbidity, EC (electrical conductivity), $\mathrm{pH}$, TDS (total dissolved solids), $\mathrm{Ca}$ (calcium), Mg (magnesium), TH (total hardness), etc. using standard available laboratory and field methods. Results of the water quality parameters were compared with WHO drinking water quality benchmarks.

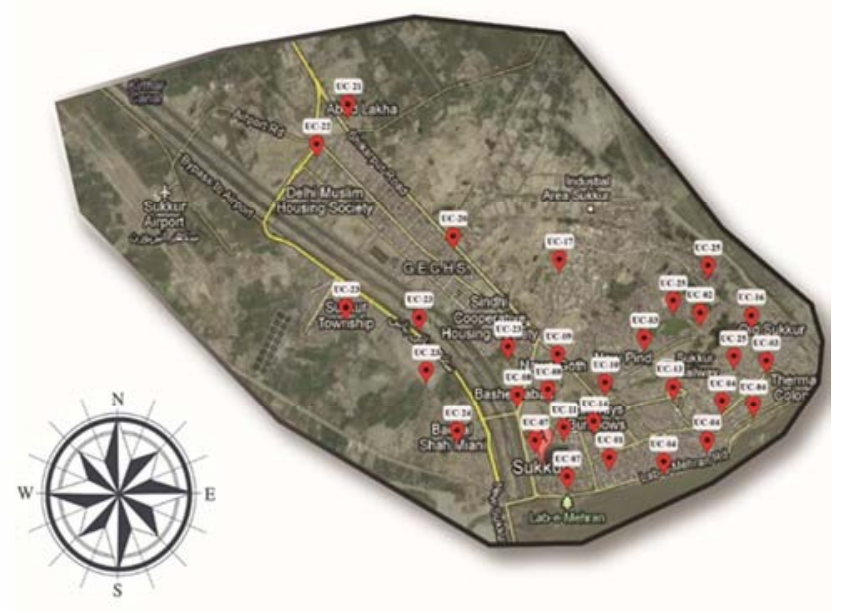

Figure 2. Groundwater Sampling Locations.

\subsection{Overall Water Quality Assessment}

The overall quality of the groundwater gathered from Sukkur City was assessed using an integrated indexical approach, i.e., the Water Quality Index (WQI) model. The WQI provides a systematic analysis of determining the suitability of the water used for multiple purposes. However, it is much hard to estimate the specific index of the groundwater [16]. Various water quality indices such as WQI (water quality index) and SPI (synthetic pollution index) are found to be useful and efficient tools used to evaluate the overall quality of water. At present, these indices have been widely used by various researchers and environmentalists around the globe to evaluate the water quality [17-20]. Hence, in this study, the WQI index model has been used to assess the overall quality of groundwater in the study area. This method was adopted by Horton [21] and developed by Brown [22] and then developed by another researcher Cude [23]. It can be applied to both surface as well as to subsurface water to assess its suitability for drinking purpose [24]. In this study, the index was determined using analysis results of various physiochemical parameters as stated earlier.

For the calculation of WQI, three steps were followed. In the first step, each of the water quality parameters was assigned a weight which is (wi) according to the significance of that parameter on the human health. The maximum weight was assigned nitrates, while the minimum value was assigned to nitrites, calcium, sulfates, and magnesium, while $\mathrm{pH}$, chloride, TDS, TH and EC were assigned weight in between 3 to 4 according to their relative significance on the human health as described in Table 1.
Table 1. Physicochemical parameters, their assigned and relative weights.

\begin{tabular}{llll}
\hline Parameter & WHO Standard & Weight (wi) & Relative weight (Wi) \\
\hline $\mathrm{pH}$ & 8.6 & 3 & 0.10 \\
Chloride & 250 & 4 & 0.13 \\
Nitrates & 10 & 5 & 0.16 \\
Nitrites & 0.02 & 2 & 0.06 \\
Calcium & 50 & 2 & 0.06 \\
Sulphates & 400 & 2 & 0.06 \\
TDS & 500 & 4 & 0.13 \\
TH & 500 & 3 & 0.10 \\
EC & 0.7 & 4 & 0.13 \\
$\mathrm{Mg}$ & 75 & 2 & 0.06 \\
& $\sum$ wi & 31 & \\
\hline
\end{tabular}

The second step was to calculate the relative weight that is (Wi) by using the following equation.

$$
W_{i}=\frac{w_{i}}{\sum_{i=1}^{n} w_{i}}
$$

Where, Wi is the relative weight, and wi is the assigned weight of each parameter.

While in the third step, to find out the quality rating (qi) for each parameter by dividing the concentration of each water sample with respective standards/WHO guidelines. The result obtained was multiplied with the 100 in order to obtain the quality rating as stated below.

$$
\mathrm{qi}=(\mathrm{Ci} / \mathrm{Si}) \times 100
$$

In which qi is the rating of water sample quality, $\mathrm{Ci}$ is the concentration of parameter of each sample having a unit of $\mathrm{mg} / \mathrm{l}$, and the $\mathrm{Si}$ is the standard of each chemical parameter. Table 1 shows the relative weights of chemical parameters used in the calculation of WQI.

For calculation of the WQI, the SI is first and foremost calculated for each of the parameters, from which in last WQI can be obtained.

$$
\begin{gathered}
\mathrm{SI}=\mathrm{Wi} \times \mathrm{qi} \\
W Q I=\sum S I i
\end{gathered}
$$

Where SI $i$ is simply a sub-index of an ith parameter, qi is the quality rating dependent on the concentration of the ith parameter, whereas $\mathrm{n}$ is the numbers of the parameter.

The WQI can be classified according to values such as excellent water, it should be $(<50)$, poor water in between 100 to 200 , very poor water ( $>200$ to 300 ), and unsuitable for drinking $(>300)[25]$.

\section{Results and Discussions}

In this study, groundwater samples gathered from various georeferenced locations of the study area were analyzed for various water quality parameters in order to determine the overall quality of groundwater. Statistical summary of various water quality parameters is described in Table 2 . 
Table 2. Statistical summary of water quality parameters.

\begin{tabular}{llllll}
\hline Parameters & Permissible Limit & Min. & Max. & Mean Value & Standard Deviation \\
\hline $\mathrm{pH}$ & 8.5 & 7.6 & 8.9 & 7.82 & 0.29 \\
Chlorides & $250 \mathrm{mg} / 1$ & 32 & 2280 & 327.73 & 565.94 \\
Nitrates & $10 \mathrm{mg} / \mathrm{l}$ & 0 & 20 & 4.13 & 6.65 \\
Nitrites & $0.02 \mathrm{mg} / \mathrm{l}$ & 0 & 4 & 0.34 & 0.92 \\
Calcium & $75 \mathrm{mg} / \mathrm{l}$ & 8 & 440 & 74.47 & 89.77 \\
Sulphates & $400 \mathrm{mg} / 1$ & 50 & 1800 & 348.33 & 400.32 \\
Total Dissolved Solids & $1000 \mathrm{mg} / 1$ & 180 & 5200 & 998.33 & 1201.01 \\
Total Hardness & $500 \mathrm{mg} / 1$ & 40 & 2150 & 378 & 465.52 \\
EC & $0.7 \mathrm{dS} / \mathrm{m}$ & 0.28 & 8.13 & 1.56 & 1.88 \\
Magnesium & $50 \mathrm{mg} / 1$ & 32 & 1710 & 303.53 & 376.92 \\
\hline
\end{tabular}

The hydrogen ion concentration $(\mathrm{pH})$ is a determination of whether water is acidic or basic. Allowable concentration of $\mathrm{pH}$ in drinking water ranges from 6.5 to 8.5. An excess amount of $\mathrm{pH}$ in the drinking water will damage the mucous membrane and supply of the water system. In this study, $\mathrm{pH}$ in the analyzed groundwater varied from 7.6 to 8.9 with a mean value of 7.78. However, groundwater collected from union council (UC)-09, UC-23, UC-04, UC-13, UC-03, UC25, UC-16, UC-17, UC-14, UC-25, UC-07, UC-08, UC-02, UC-24, UC-22, UC-07, UC-03, UC-01, UC-11, UC-21, UC10 have the desirable limit of $\mathrm{pH}$ and the UC-20 have $\mathrm{pH}$ above 8.5 .

EC is a measurement of an aquatic solution of water to carry an electric current. It is used for many purposes related to the quality of water, this helps to determine and analyze the mineralization, natural water changes, and wastewater. Also, it is used for the determination of chemical reagents to be mixed in water. In this study, EC values ranged between 0.28 to $8.13 \mathrm{dS} / \mathrm{m}$, with its mean value as $1.56 \mathrm{dS} / \mathrm{m}$. However, its allowable limit for drinking water is $0.7 \mathrm{dS} / \mathrm{m}$. In this study, water collected from UC-09, UC-13, UC-03, UC-25, UC-17, UC-14, UC-25, UC-08, UC-02, UC-23, UC03, UC-11, UC-20 have a desirable limit of EC. Whereas, groundwater of UC-23, UC-04, UC-04, UC-16, UC-25, UC07, UC-24, UC-22, UC-01, UC-08, UC-21, UC-10 have an excess amount of EC.

TDS in the water may develop from natural sources, such as water in livestock, sewages, soil nature, and industrial waste. In the study area, TDS values ranged from 180 to $5200 \mathrm{mg} / \mathrm{l}$ with its mean value of $998.3 \mathrm{mg} / \mathrm{l}$. The desirable limit of TDS in drinking water as per WHO is $1000 \mathrm{mg} / \mathrm{l}$. In this study, it was found that UC-09, UC-04, UC-16, UC-25, UC-07, UC-04, UC-08, UC-24, UC-22, UC-07, UC-01, UC21, UC-10 have the desirable limit of TDS in the groundwater. Whereas, UC-23, UC-13, UC-03, UC-25, UC17, UC-14, UC-02, UC-03, UC-11, UC-20 have an excess amount of TDS in drinking water.

The magnesium $(\mathrm{Mg})$ ranged from $32 \mathrm{mg} / \mathrm{l}$ to $1710 \mathrm{mg} / \mathrm{l}$ with its mean value of $303.53 \mathrm{mg} / \mathrm{l}$. WHO (2006) has recommended its permissible limit as $50 \mathrm{mg} / \mathrm{l}$. In the study area, groundwater collected from UC-23 and UC-01 have the desirable limit of $\mathrm{Mg}$, whereas UC-09, UC-23, UC-04, UC13, UC-03, UC-25, UC-16, UC-17, UC-14, UC-25, UC-07,
UC-08, UC-02, UC-24, UC-22, UC-07, UC-03, UC-01, UC11, UC-21, UC-10 have an excess amount of $\mathrm{Mg}$.

Nitrites and Nitrates are some sort of salts which can be natural as well as artificially present in the groundwater, Nitrites come from the fertilizers mainly, run-off water, mineral deposits, and sewage. In the study amount of nitrites in the groundwater ranged from 0 to $4 \mathrm{mg} / \mathrm{l}$ with its mean value of $0.34 \mathrm{mg} / \mathrm{l}$. However, nitrates amount in the groundwater of the study area ranged from 0 to $20 \mathrm{mg} / \mathrm{l}$ with its average value of $4.13 \mathrm{mg} / \mathrm{l}$. In this way, it was found that UC-09, UC-23, UC-04, UC-13, UC-04, UC-25, UC-07, UC24, UC-22, UC-03, UC-23, UC-01, UC-08, UC-21, UC-10 have the desirable limit of nitrites in the groundwater. Whereas, UC-16, UC-17, UC-14, UC-08, UC-02, UC-11, $\mathrm{UC}-20$ have an excess amount of nitrites in the ground water. Similarly, it was found that UC-09, UC-23, UC-04, UC-03, UC-25, UC-16, UC-14, UC-07, UC-08, UC-23, UC-24, UC22, UC-03, UC-01, UC-08, UC-21, UC-10 have groundwater having desirable limit of nitrates. However, UC-13, UC-17, UC-25, UC-04, UC-02, UC-11 have an excess amount of nitrates in the groundwater.

The calcium (Ca) amount ranged between $8 \mathrm{mg} / \mathrm{l}$ to 440 $\mathrm{mg} / \mathrm{l}$ with its mean value of $74.47 \mathrm{mg} / \mathrm{l}$. WHO have suggested the desirable value of $75 \mathrm{mg} / \mathrm{l}$. From this study, it was found that UC-23, UC-04, UC-03, UC-25, UC-16, UC07, UC-08, UC-24, UC-22, UC-07, UC-01, UC-21, UC-10 have the desirable calcium level in the drinking water whereas, UC-09, UC-13, UC-17, UC-14, UC-02, UC-11, $\mathrm{UC}-20$ have an excess amount of lime calcium in the groundwater.

Chloride is the mixture of the chlorine gas with metal and some minor materials of earth crust but major dissolved minerals of most natural water. There are many sources through which chloride dissolve in water, which are heavy industrial waste, waste obtained from the treatment plants, Chloride can harm freshwater and lake water. In the study area, the chloride content ranged from $32 \mathrm{mg} / \mathrm{l}$ to $2280 \mathrm{mg} / \mathrm{l}$ with a mean value of $327.73 \mathrm{mg} / \mathrm{l}$. WHO has suggested its desirable limit of $250 \mathrm{mg} / \mathrm{l}$. From this study, it was found that UC-23, UC-04, UC-13, UC-03, UC-25, UC-16, UC-17, UC14, UC-07, UC-08, UC-23, UC-24, UC-22, UC-07, UC-01, UC-11, UC-20, UC-21, UC-10 have the desirable limit of the chloride in the drinking water, whereas, UC-09, UC-11, UC- 
20 , UC21 have an excess amount of chloride in the drinking water.

Total hardness is the percentage of calcium and magnesium present in the water. Generally, surface water as compared to groundwater is softer. WHO has suggested its desirable limit as $300 \mathrm{mg} / \mathrm{l}$. In the study area, the hardness in the groundwater ranged from $40 \mathrm{mg} / 1$ to $2150 \mathrm{mg} / \mathrm{l}$ with its mean value of $378 \mathrm{mg} / \mathrm{l}$. From this study, it was found that UC-23, UC-04, UC-03, UC-25, UC-16, UC-07, UC-24, UC22, UC-03, UC-01, UC-08, UC-21 have the desirable limit of total hardness in the drinking water, whereas, UC-09, UC-13, UC-17, UC-14, UC-25, UC-08, UC-02, UC-23, UC-11, UC$20, \mathrm{UC}-10$ have an excess amount of hardness in the drinking water.
The Sulfate can be natural or artificial, Naturally, it originates from rocks or soil. Artificially it is formed from the fertilized land runoff. Sulfur is one of the most important nutrients for the plant. WHO has suggested its desirable limit as $400 \mathrm{mg} / \mathrm{l}$. In this study, the sulfate ranged from $50 \mathrm{mg} / \mathrm{l}$ to $1800 \mathrm{mg} / \mathrm{l}$ with a mean value of $348.33 \mathrm{mg} / \mathrm{l}$. Present study revealed that UC-23, UC-04, UC-03, UC-25, UC-16, UC-07, UC-08, UC-24, UC-22, UC-23, UC-01, UC-21, UC-10 have the desirable limit of sulfate in the drinking water, whereas, UC-09, UC-13, UC-17, UC-14, UC-02, UC-03, UC-11, UC20 have an excess amount of hardness in the drinking water. Analysis based on the WQI

Table 3 presents the classifications of the sampled groundwater, based on the application of the WQI model.

Table 3. Classifications of Sampled Groundwater based on the WQI model.

\begin{tabular}{|c|c|c|c|c|c|}
\hline Sample No. & $W Q I=\sum W i * q i$ & Category of water & Sample No. & $W Q I=\sum W^{*} q i$ & Category of water \\
\hline S:01 & 674.97 & Unsuitable for drinking & $\mathrm{S}: 16$ & 55.22 & Good water \\
\hline S:02 & 57.27 & Good water & S:17 & 511.12 & Unsuitable for drinking \\
\hline S:03 & 60.18 & Good water & $\mathrm{S}: 18$ & 101.61 & Poor water \\
\hline S:04 & 188.10 & Poor water & $\mathrm{S}: 19$ & 49.57 & Good water \\
\hline S:05 & 42.15 & Good water & $\mathrm{S}: 20$ & 42.06 & Good water \\
\hline S:07 & 113.81 & Good water & $\mathrm{S}: 22$ & 59.21 & Good water \\
\hline S:08 & 67.66 & Good water & $\mathrm{S}: 23$ & 141.28 & Poor water \\
\hline S:09 & 1379.32 & Unsuitable for drinking & $\mathrm{S}: 24$ & 65.16 & Good water \\
\hline $\mathrm{S}: 10$ & 1060.86 & Unsuitable for drinking & $\mathrm{S}: 25$ & 35.02 & Good water \\
\hline $\mathrm{S}: 11$ & 139.02 & Poor water & S:26 & 48.02 & Good water \\
\hline $\mathrm{S}: 12$ & 36.48 & Excellent water & S:27 & 749.33 & Unsuitable for drinking \\
\hline $\mathrm{S}: 14$ & 93.74 & Good water & $\mathrm{S}: 29$ & 138.25 & Poor water \\
\hline $\mathrm{S}: 15$ & 395.53 & Unsuitable for drinking & $\mathrm{S}: 30$ & 82.96 & Good water \\
\hline
\end{tabular}

The WQI of Sukkur City ranged from 35.31 to 1379.47 with its mean value of 238.22 . However, estimations of the WQI revealed that $2 \%$ of the water samples were excellent, $52 \%$ good, $22 \%$ poor, and $24 \%$ unsuitable for drinking purpose as depicted in Figures 3 and 4.

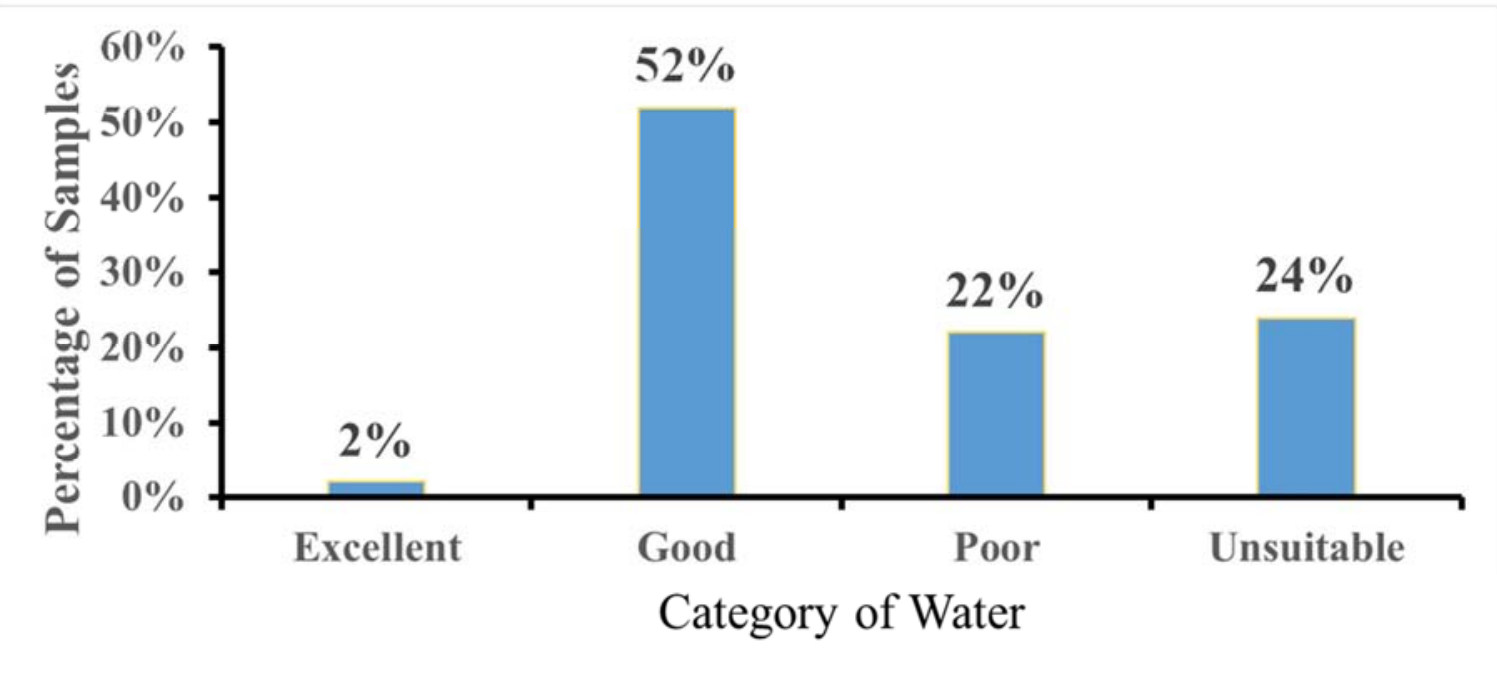

Figure 3. Overall status of Groundwater based on the WQI. 


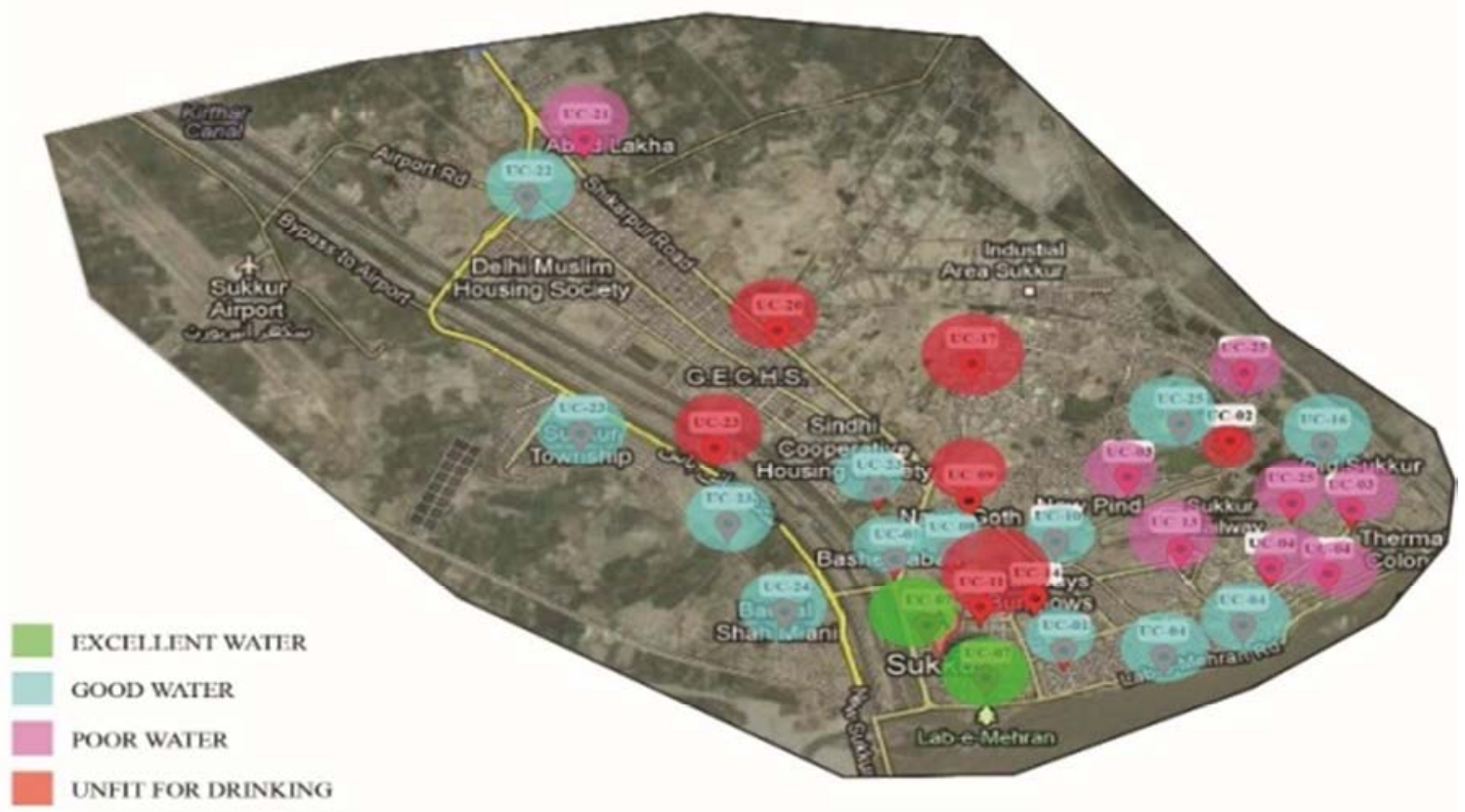

Figure 4. Overall status of Groundwater Quality based on the WQI model.

\section{Conclusion}

The analysis revealed that $\mathrm{pH}$ in the groundwater samples gathered from the study area ranged from 7.6 to 8.8 . The chloride concentration ranged between 32 to $2280 \mathrm{mg} / \mathrm{l}$. The calcium level ranged between 8 to $440 \mathrm{mg} / \mathrm{L}$. The magnesium concentration observed between 32 to $1710 \mathrm{mg} / \mathrm{l}$. The TH level ranged between 40 to $2150 \mathrm{mg} / \mathrm{l}$. The EC and TDS ranged between 0.28 to $8.13 \mathrm{dS} / \mathrm{m}$, and 180 to 5200 $\mathrm{mg} / \mathrm{l}$ respectively.

In the study, we found out that groundwater in the UC-09, UC-14 have excessive amount of chlorides, UC-13, UC-17, UC-25, UC-4 have excessive amount of Nitrates, UC-03, UC-17, UC-16, UC-14, UC-08 have excessive amount of Nitrites, UC-09 have excessive amount of lime calcium, UC09, UC-13, UC-17, UC-14, UC-02, UC-03, UC-11, UC-20 have excessive amount of Sulfates, UC-23, UC-13, UC-03, UC-25, UC-17, UC-14, UC-02, UC-03, UC-11, UC-20 have excessive amount of TDS, UC-09, UC-13, UC-17, UC-14, UC-25, UC-08, UC-02, UC-23, UC-11, UC-20, UC-10 have excessive amount of hardness, UC-09, UC-23, UC-04, UC13, UC-03, UC-25, UC-16, UC-17, UC-14, UC-25, UC-07, UC-08, UC-02, UC-24, UC-22, UC-07, UC-03, UC-01, UC11, UC-21, UC-10 have excessive amount of Magnesium,

Moreover, analysis based on the WQI revealed that the $\mathrm{UC}-25$, UC-07 have excellent water quality, UC-23, UC-04, UC-25, UC-16, UC-24, UC-22, UC-07, UC-01, UC-08, UC10 have good water quality, UC-13, UC-03, UC-25, UC-03, $\mathrm{UC}-21$ have poor water quality, and UC-09, UC-17, UC-14, UC-02, UC-11, UC-20 having water unsuitable for drinking purposes. Overall status of water quality reveals that at some of the areas of the Sukkur city have poor quality groundwater, thus it should be treated before its use for domestic purposes.

\section{References}

[1] Solangi, G. S., Siyal, A. A., Babar, M. M., Siyal, P. (2020). Groundwater Quality Evaluation using the Water Quality Index (WQI), the Synthetic Pollution Index (SPI) and Geospatial tools: a case study of Sujawal District, Pakistan. Human and Ecological Risk Assessment: An International Journal, Volume 26, No. 6, pp. 1529-1549.

[2] Santhosh, P., Revathi, D. (2014). Hydrogeochemical Analysis of Ground Water Parameters in Coimbatore District, Tamilnadu, India Research Journal of Chemical and Environmental Sciences. Res J. Chem. Environ. Sci. Vol 2 April 2014: 89-93.

[3] Arulbalaji, P., Gurugnanam, B. (2017). Groundwater quality assessment using geospatial and statistical tools in Salem District, Tamil Nadu, India. Appl Water Sci (2017) 7: 2737-2751.

[4] Ouyang, Y., 2005. Evaluation of river water quality monitoring stations by principal component analysis. Water Res. 39, 2621-2635.

[5] Solangi, G. S., Siyal, A. A., Babar, M. M., Siyal, P. (2019). Application of water quality index, synthetic pollution index, and geospatial tools for the assessment of drinking water quality in the Indus Delta, Pakistan. Environmental Monitoring and Assessment.

[6] Solangi, G. S., Siyal, A. A., Babar, M. M., Siyal, P. (2019). Evaluation of Drinking water quality using the Water Quality Index (WQI), the Synthetic Pollution Index (SPI) and Geospatial tools in Thatta District, Pakistan. Desalination and Water Treatment Journal, Vol. 160, pp. 202-213.

[7] Bhatti, N. B., Siyal, A. A., Qureshi, A. A., Solangi, G. S., Memon, N. A., Bhatti, I. A. (2019). Impact of small dam's construction on groundwater quality and level using water quality index (WQI) and GIS: Nagarparkar area of Sindh, Pakistan. Human and Ecological Risk Assessment: An International Journal. 
[8] Solangi, G. S., Siyal, A. A., Babar, M. M., Siyal, P. (2018). Evaluation of surface water quality using the Water Quality Index (WQI), and the Synthetic Pollution Index (SPI): A case study of Indus Delta region of Pakistan. Desalination and Water Treatment Journal, Vol. 118, pp. 39-48.

[9] Solangi, G. S., Siyal, A. A., Siyal, P. (2019). Analysis of Indus Delta Groundwater and Surface water Suitability for Domestic and Irrigation Purposes. Civil Engineering Journal, Volume 5, Issue 7, pp. 1599-1608.

[10] Akram, P., Solangi, G. S., Shehzad, F. R., Kandhro, A. A., Arain, S. S., Kamboh, M. A. (2020). Groundwater Quality Assessment using a Water Quality Index (WQI) in Nine Major Cities of Sindh, Pakistan. International Journal of Research in Environmental Science (IJRES) Volume 6, Issue 3, 2020, pp. $18-26$

[11] Solangi, G. S., Siyal, A. A., Babar, M. M., Siyal, P. (2017). Groundwater Quality Mapping using Geographic Information System: A Case Study of District Thatta, Sindh, Pakistan. Mehran University Research Journal of Engineering \& Technology, Vol. 36, 4, pp. 1059-1072.

[12] Pesce, S. F., Wunderlin, D. A. (2000). Use of water quality indices to verify the impact of Cordoba city (Argentina) on Suquia river. Water Res. 34 (11), 2915-2926.

[13] Subramani, T., Rajmohan, N., Elango, L. (2009). Groundwater geochemistry and identification of hydrogeochemical processes in a hard rock region, Southern India. Environ. Monit. Assess. 162 (1-4), 123-137.

[14] Abbasnia, A., Alimohammadi, M., Mahvi, AH., et al. (2018). Assessment of groundwater quality and evaluation of scaling and corrosiveness potential of drinking water samples in villages of Chabahr city, Sistan and Baluchistan province in Iran. Data Brief 16: 182-92.

[15] Egbueri, J. C., \& Unigwe, (2019). An integrated indexical investigation of selected heavy metals in drinking water resources from a coastal plain aquifer in Nigeria. Springer Nature Switzerland AG 2019.

[16] S. K. Singh, P. K. Srivastava, D. Singh, D. Han, S. K. Gautam, A. C. Pandey, modelling groundwater quality over a humid subtropical region using numerical indices, earth observation datasets, and X-ray diffraction technique: a case study of Allahabad district, India, Environ. Geochem. Health, 37 (2015) 157-180.

[17] Ketata-Rokbani M, Gueddari M, and Bouhlila R. 2011. Use of geographical information system and water quality index to assess groundwater quality in El Khairat Deep Aquifer (Enfidha, Tunisian Sahel). Iranica. J. Energy Environ. 2 (2): 133-144.

[18] Shabbir R, and Ahmad SS. 2015. Use of Geographic Information System and Water Quality Index to Assess Groundwater Quality in Rawalpindi and Islamabad. Arab J. of Sci. Eng., 40: 2033-2047.

[19] Ewaid SH, and Abed SA. 2017. Water quality index for AlGharraf River, southern Iraq. Egyptian Journal of Aquatic Research.

[20] Khangembam S, and Kshetrimayum KS. 2019. Evaluation of hydrogeochemical controlling factors and water quality index of water resources of the Barak valley of Assam, Northeast India. Groundwater for Sustainable Development, Available online 12 February 2019.

[21] R. K. Horton, An index number system for rating water quality, J. Water Pollut. Control Fed., 37 (1965) 300-306.

[22] R. M. Brown, N. I. McClelland, R. A. Deininger, R. G. Tozer, Water quality index-do we dare? Water Sewage Works, 117 (1970) 339-343.

[23] C. Cude, Oregon water quality index: a tool for evaluating water quality management effectiveness, J. Am. Water Res. Assoc., 37 (2001) 125-137.

[24] S. Tyagi, B. Sharma, P. Singh, R. Dobhal, Water quality assessment in terms of water quality index, Am. J. Water Res., 1 (2013) 34-38.

[25] E. Hoseinzadeh, H. Khorsandi, C. Wei, M. Alipour, Evaluation of Aydughmush river water quality using the national sanitation foundation water quality index (NSFWQI), river pollution index (RPI), and forestry water quality index (FWQI), Desalin. Water Treat. 54 (11) (2014) 2994-3002. 